\section{Eyelid dermatitis caused by allergic contact to acrylates in artificial nails}

\author{
Jorge Moreira, Rita Gonçalves, \\ Pedro Coelho, Tiago Maio \\ Department of Ophthalmology, Hospital \\ Pedro Hispano, Porto, Portugal
}

\begin{abstract}
Over the past few years, there has been an increase in cases of allergic contact dermatitis caused by acrylates, because of the growing popularity of artificial nails. Pathological reactions to artificial nails typically occur on or around the nail area. Eyelid contact dermatitis due to artificial nails is rarely seen, especially in a nonoccupational setting. The authors report the case of a 45-year-old female accountant who developed eyelid dermatitis due to artificial nails.
\end{abstract}

\section{Introduction}

The eyelid is one of the most sensitive areas of the body as the skin of the eyelid is extremely thin and is exposed to an extraordinary number of substances. For this reason, eyelid dermatitis is a common disease, and a variety of factors, including primary skin diseases and external insults may cause eyelid erythema. Determining the underlying etiology may prove especially challenging, because eyelid rashes, regardless of the cause, look very similar.

Allergic contact dermatitis (ACD) is considered the most common cause of eyelid dermatitis, and its prevalence ranges from $46 \%$ to $74 \%{ }^{1,2}$

Acute ACD often presents with intense pruritus and a well-demarcated erythema of the eyelids whereas subacute and chronic forms are less erythematous, and are characterized by dry, scaly and lichenified skin. ${ }^{3}$

The list of allergens that are potentially associated is extensive, and it includes topical pharmaceutical products, cosmetics, metals, rubber derivatives, and plants. ${ }^{4}$ The causal contact allergens may be of occupational or non-occupational origin and may come into contact with the eyelid skin in several ways. Most often, eyelid contact dermatitis is the result not from direct periocular exposure, but rather due to ectopic reactions, caused by substances applied to the hair, face, scalp or fingernails. ${ }^{5}$ The eyelid is also particularly susceptible to ACD from airborne allergens. ${ }^{5}$ Due to its exceptional vulnerability, eyelid skin may be the initial or only area that demonstrates signs of contact dermatitis, while other areas of the body remain unaffected by the same exposure. 5

Here, we present the case of a woman who developed eyelid dermatitis due to acrylates in artificial nails.

\section{Case Report}

A 45-year-old female accountant presented with a one-week history of a pruritic and symmetric redness of the eyelids.

Examination showed edema and a welldefined erythema of both eyelids (Figure 1). At the slit lamp exam, eye examination was normal. There was no personal or family history of atopy.

A detailed history of her exposures revealed that she wore photobonded acrylic gel nails. She had no skin lesions elsewhere, namely on the hands, periungual area or nails.

Patch tests with the Portuguese Standard and Acrylates series (Chemotechnique ${ }^{\circledR}$ Diagnostics, Vellinge, Sweden) applied using Finn ${ }^{\circledR}$ Chambers on Scanpor ${ }^{\circledR}$ tape (Epitest Ltd Oy, Tuusula, Finland) were performed and readings at D2 and D4 revealed positive reactions to ethylacrylate $1 \%(++)$, methyl metacrylate monomer $10 \%(+)$, and 2-hydroxyethylmethacrylate $(++)$.

The results were consistent with the diagnosis of allergic contact dermatitis to artificial nails containing acrylates.

The eyelid dermatitis resolved following application of topical corticosteroid and removal of the artificial nails.

\section{Discussion}

Acrylates are plastic materials that are formed by the polymerization of monomers derived from acrylic or methacrylic acid. They can be found in a wide variety of products, including adhesives, glues, paints, and artificial nails.

Acrylates are well-known for their sensitizing potential, and for causing ACD in those exposed to the monomers. Classically, ACD caused by acrylates was considered primarily an occupational disease, affecting mainly dentists, prosthesis technicians, painters, and workers in the fiberglass and graphic printing industries. ${ }^{6}$ In the last few years, with the widespread use of artificial nails, an increasing number of cases of allergic contact dermatitis caused by acry-
Correspondence: Jorge Moreira, Department of Ophthalmology, Hospital Pedro Hispano, Rua Dr. Eduardo Torres, 4464-513, Senhora da Hora, Porto, Portugal.

Tel.: +351.229391000.

E-mail: jorgemoreira.fm@gmail.com

Key words: Eyelid; contact dermatitis; artificial nails; acrylates.

Acknowledgments: we thank the Department of Dermatology for all the help in this clinical case.

Contributions: JM, Conception of the work; data collection, and interpretation; drafting and revising the manuscript; literature review; final approval of the manuscript to be published. RG, PC, TM, analysis and interpretation of data; manuscript review; literature review; final approval of the manuscript to be published.

Conflict of interest: the authors declare no potential conflict of interest.

Received for publication: 23 April 2017.

Accepted for publication: 22 May 2017.

This work is licensed under a Creative Commons Attribution-NonCommercial 4.0 International License (CC BY-NC 4.0).

(C) Copyright J. Moreira et al., 2017

Licensee PAGEPress, Italy

Dermatology Reports 2017; 9:7198

doi:10.4081/dr:2017.7198

lates have been reported particularly in nail technicians, but also among artificial nail users..$^{7-9}$

Exposure to acrylates in artificial nails may induce a wide variety of clinical manifestations. Reactions in nail users, most commonly, occur on or around the nail area, and include paronychia, onychodystrophy, onycholysis, nail bed hyperkeratosis, painful nails, and occasionally, paresthesia. ${ }^{10,11}$ In the case of the nail technicians, the most frequent adverse reaction is hand dermatitis, through manipulation of unpolymerized acrylates. ${ }^{\text {? }}$

Unlike what happens with traditional nail varnishes, ACD caused by the acrylates present in the artificial nails usually produces lesions at the site of application to the nail itself, and only very rarely affects distant areas, such as the face and eyelids. ${ }^{7,8,12}$ Distant ACD can be explained by hand transportation or airborne dissemination of the allergen. ${ }^{13}$

The acrylate monomer is a powerful sensitizer, whereas the polymer is significantly weaker or non-sensitizing, and because of this feature, distant allergic reactions to acrylate-containing artificial nails 


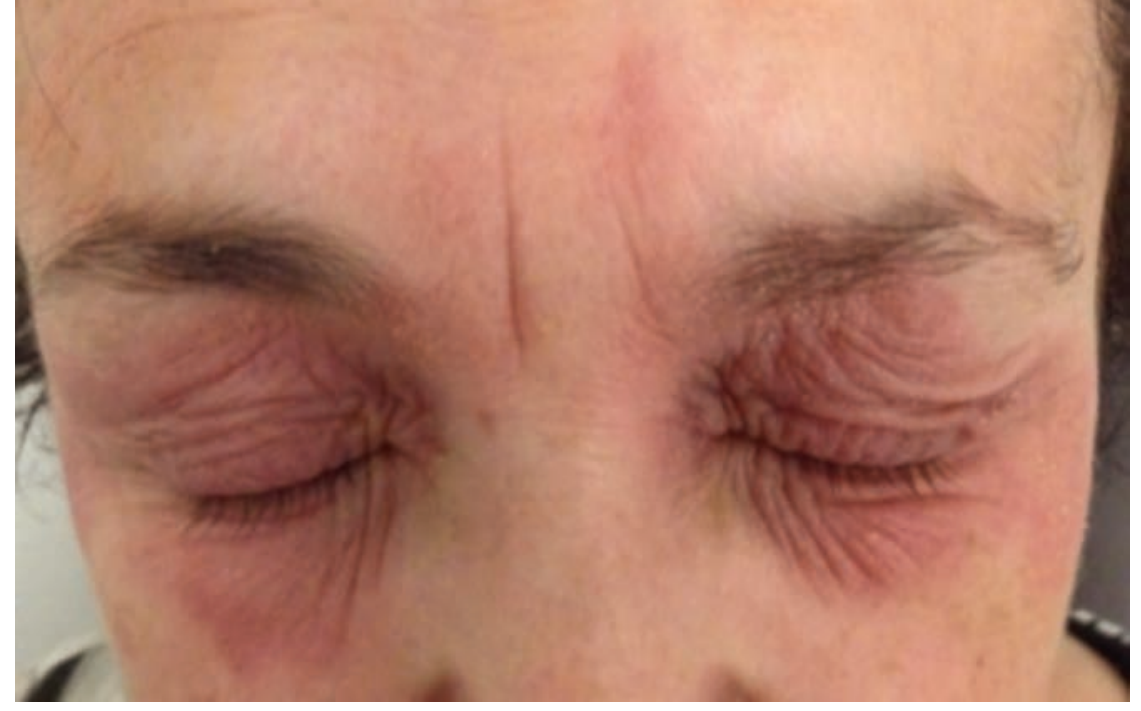

Figure 1. Periorbital eczema.

are uncommon. ${ }^{5,6}$ In our case, contact with monomer might have occurred before polymerization, or small amounts of monomer might have remained unpolymerized, or the filling process of completely polymerized resins might have released the monomer. ${ }^{11,14}$

\section{Conclusions}

Contact dermatitis is the most common cause of eyelid dermatitis, therefore, a detailed exposure history is essential for an accurate diagnosis and successfull management. This report highlights a hypersensitivity reaction to artificial nails involving an unusual location, particularly in a non-occupational setting, and stresses the importance of considering nail cosmetics in the evaluation of eyelid dermatitis.
Contact Dermatitis 2001;44:153-9.

7. Roche E, de la Cuadra J, Alegre V. Sensitization to acrylates caused by artificial acrylic nails: review of 15 cases. Actas Dermosifiliogr 2008;99:788-94.

8. Ramos L, Cabral R, Gonçalo M. Allergic contact dermatitis caused by acrylates and methacrylates - a 7-year study. Contact Dermatitis 2014;71:1027.

9. Montgomery R, Stocks SJ, Wilkinson SM. Contact allergy resulting from the use of acrylate nails is increasing in both users and those who are occupationally exposed. Contact Dermatitis 2016;74:120-2.

10. Cruz MJ, Baudrier T, Cunha AP, et al. Severe onychodystrophy caused by allergic contact dermatitis to acrylates in artificial nails. Cutan Ocul Toxicol 2011;30:323-4.

11. Freeman S, Lee MS, Gudmundsen K. Adverse contact reactions to sculptured acrylic nails: 4 case reports and a literature review. Contact Dermatitis 1995;33:381-5.

1. Nethercott JR, Nield G, Holness DL. A review of 79 cases of eyelid dermatitis. J Am Acad Dermatol 1989;21:223-30.

2. Guin JD. Eyelid dermatitis: experience in 203 cases. J Am Acad Dermatol 2002;47:755-65.

3. Peralejo B, Beltrani V, Bielory L. Dermatologic and allergic conditions of the eyelid. Immunol Allergy Clin North Am 2008;28:137-68.

4. Goossens A. Contact allergic reactions on the eyes and eyelids. Bull Soc Belge Ophtalmol 2004;292:11-7.

5. Rietschel RL, Fowler JF Jr. Fisher's contact dermatitis, $6^{\text {th }}$ ed. Hamilton, ON: BC Decker; 2008. pp 1-7; 731-741.

6. Geukens, Goossens A. Occupational contact allergy to (meth)acrylates.
12. Baran R. Nail beauty therapy: an attractive enhancement or a potential hazard? J Cosmet Dermatol 2002;1:24-9.

13. Lazarov A. Sensitization to acrylates is a common adverse reaction to artificial fingernails. J Eur Acad Dermatol Venereol 2007;21:169-74.

14. Maio P, Carvalho $R$, Amaro $C$, et al. Allergic contact dermatitis from sculptured acrylic nails: special presentation with an airborne pattern. Dermatol Reports 2012;4:e6. 